extreme enough to result in negligible diapause, with a corresponding failure of the overwintering population attended by a crash next year, or conversely, whether an unusually high percentage might enter diapause, with a heavy moth flight the following year.

The experiments reported here were performed while the author was em- ployed at the Canada Agriculture Research Station, 107 Science Crescent, Saskatoon, Saskatchewan. S7N $0 \times 2$, using the Station's laboratory and greenhouse facilities.

'DANILEVSKII, A.S. 1965. Photoperiodism and seasonal development of insects. Oliver and Boyd. 283 pp ix.

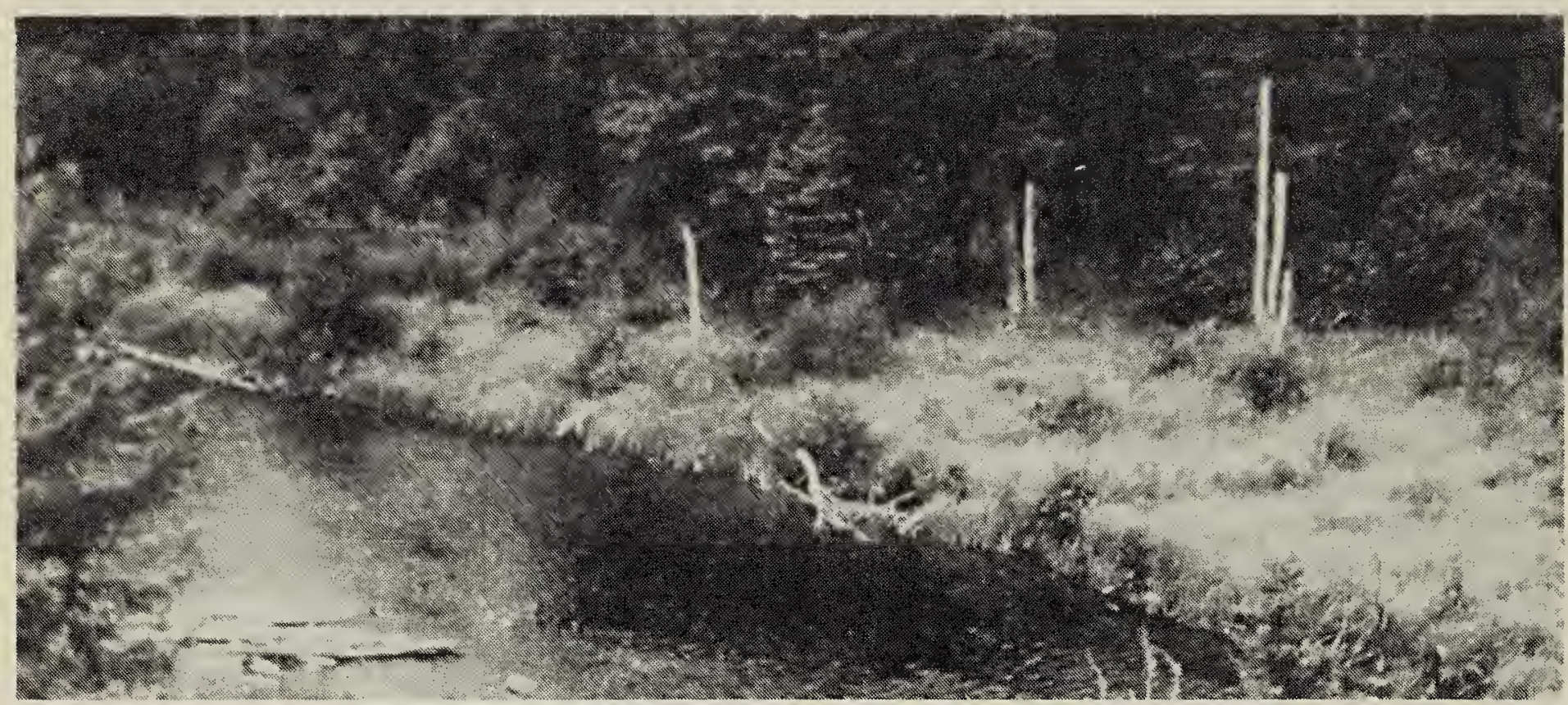

MacLennan River, Prince Albert National Park

Blake Maybank

\title{
OF ICE WORMS AND SNOW FLEAS
}

ALAN R. SMITH and A. LINDA LAHEY, 614 Lansdowne Avenue, Saskatoon. S7N $1 E 3$

On 13 March 1983, a warm springlike day in northern Saskatchewan, we were walking down the trail to Trappers Lake in Prince Albert National Park when we noticed that the snow was covered with what appeared to be soot. A closer examination revealed the prescence of millions of tiny insects. At that time the only thing we knew about them was that they were called "snow fleas".

The thought that cold-blooded animals of any kind can tolerate or even thrive in the snow is bound to cause scepticism. But "ice worms" and "snow fleas" do exist. Ice worms are oligochaete worms that actually live and breed in the snow of glaciers. Snow fleas are members of the insect order Collembola which are familiarly known as springtails. The most commonly-occurring snow flea is Achorutes nivicolis (Fitch); it is this species that we believe we saw at Trappers Lake on this day and two weeks later on 27 March. 


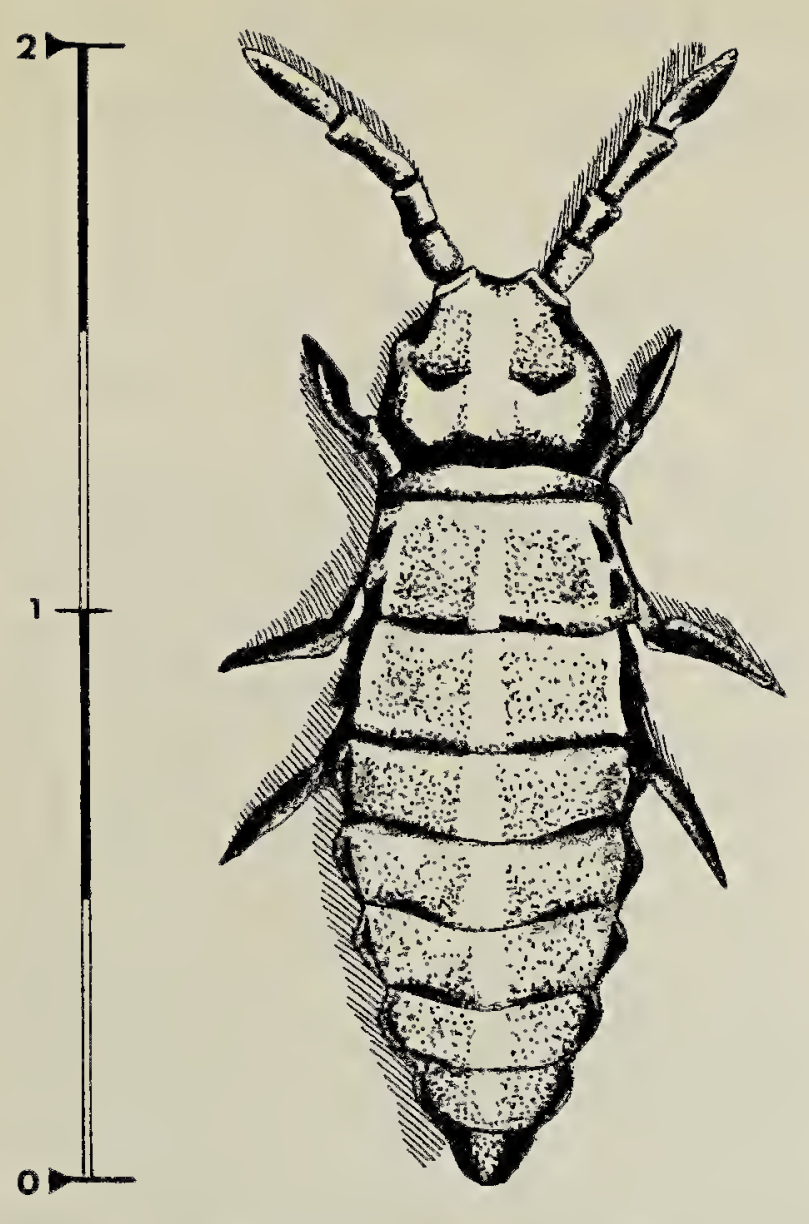

Figure 1: Adult snow flea. Scale in $\mathrm{mm}$.

Snow fleas are primitive insects; they are wingless and have incomplete metamorphosis (that is they hatch out as miniature adults). The body consists of nine segments, the first three of which possess legs (see Figure 1). The most striking feature, and the one to which the springtails owe their name, is the leaping apparatus. This is attached to the underside of the seventh segment and is known as the furcula. While at rest the furcula is bent forward under the body and held under tension by the double-fingered appendage on the sixth segment known as the tenaculum. If the tenaculum is relaxed the muscle at the base of the furcula pulls strongly downwards and hurls the insect as much as $15 \mathrm{~cm}(6$ inc.) into the air. While aloft the furcula is folded back into position in preparation for the next jump. Leaping, however, is generally only used to escape danger as the usual mode of locomotion is walking.

Little is known about the life history of snow fleas. The eggs are about 0.10 $\mathrm{mm}$ in diameter and are laid in masses of 50 to 100 . The young at hatching are white but grow darker with age. Snow fleas are sexually mature at a length of $1.25 \mathrm{~mm}$ and attain a maximum length of $2.00 \mathrm{~mm}$. The main food appears to be organic detritus which is gleaned from their forest floor habitat. When food supplies become exhausted the species begins to swarm. Although this phenomenon can occur any time surface temperatures are at or above freezing, swarming is only noticeable to the casual observer when there is snow cover. At this time the minute insects climb up through the interstices of snow crystals or along plant stems to accumulate on the surface of the snow where their tiny black bodies contrast with the whiteness of the snow.

We noticed snow fleas in only one location: in a strip $5 \times 100 \mathrm{~m}$ along the trail to the lake. The winding trail runs through heavy mixed woods so perhaps the swarming occurred on the only stretch of the trail where trees did not block the sun's warming rays. The sight was remarkable: tiny black bodies were leaping everywhere. They were particularly abundant in ski tracks and footprints. One ski track contained snow fleas several millimetres thick!

For those interested in learning more about springtails in general and snow fleas in particular, we refer you to an article by Charles MacNamara which appeared in the Canadian Entomologist in 1919'. The descriptions of snow flea anatomy and life history presented in this paper are mere summaries of the many interesting facts found in MacNamara's article.

'MacNAMARA, CHARLES. 1919. Popular and Practical Entomology - Remarks on Collembola. The Canadian Entomologist, LI(4):72-80; (11):240-245; (12):265-271. 